\title{
Mitigating Heat Stress By Dietary Manipulation of Dried Pulp of Tamarind (Tamarindus Indica L.) In Broilers Ration: Growth Dynamics, Lipids Profile, Redox Balance, Cellular And Humoral Immune Response
}

Mah Hassan ( $\square$ rukhan@aup.edu.pk)

The University of Agriculture

Naila Chand

The University of Agriculture

Rifat Ullah Khan

The University of Agriculture

Research Article

Keywords: Broiler, growth, redox, lipids, Tamarind

Posted Date: June 22nd, 2021

DOI: https://doi.org/10.21203/rs.3.rs-611581/v1

License: (c) (1) This work is licensed under a Creative Commons Attribution 4.0 International License.

Read Full License 


\section{Abstract}

A total of 700 day old broiler chicks (Arbor Acres) were weighed and allocated to 28 floor pens ( 25 birds per pen). Five diets were prepared and allocated in a completely randomized design consisting of a control (basal diet) and four levels of dried Tamarind seeds pulp (DTSP) powder at the rate of 5 (DTSP-5), 7.5 (DTSP-7.5), 10 (DTSP-10) and 12.5 (DTSP-12.5) g/ kg of feed for 35 days under heat stress condition. Body weight and feed conversion ratio $(F C R)$ increased significantly $(P<0.05)$ in the DTSP fed broilers compared to the control. Blood concentration of paraoxonase-1 (PON1) was significantly $(P<0.05)$ higher in the DTSP-10 and DTSP-12.5 compared to the control. However, antibody titre against New Castle disease (ND) was significantly $(\mathrm{P}<0.05)$ higher in DTSP-7, DTSP-10 and DTSP-12.5 compared to the control. Blood cholesterol and triglyceride were significantly $(P<0.05)$ lower in DTSP-7, DTSP-10 and DTSP4-12.5 compared to the control. However, blood HDL was significantly $(P<005)$ higher in DTSP-10 and DTSP-12.5 compared to the control. Blood LDL was significantly $(P<0.05)$ lower in DTSP-7, DTSP-10 and DTSP-12.5 compared to the control. Significantly $(P<0.05)$ higher total leucocytes count $(T L C)$ was found in DTSP-12.5, however, heterophils were significantly $(P<0.05)$ lower in the same group. In contrast, lymphocytes increased significantly $(P<0.05)$ in DTSP-7, DTSP-10 and DTSP-12.5 while monocytes was significantly $(P<0.05)$ decreased in the same group. In conclusion, DTSP-5 supplementation improved growth, however, redox balance, cholesterol profile and cellular and humoral immunity increased in DTSP5, DTSP-7.5 and DTSP-12.5 in broilers exposed to heat stress.

\section{Introduction}

Though there is no universal definition of heat stress, however, it can be defined as environmental temperature beyond physiological temperature of the body, which results in adverse consequences and ultimately reduces the growth performance of the broiler chickens (Khan et al. 2012). In poultry production, heat stress occurs when the ambient temperature exceeds $25^{\circ} \mathrm{C}$. The heat exposure may be from several days to several weeks and the temperature may go as high as $50^{\circ} \mathrm{C}$ (Kpomasse et al. 2021). Research studies have reported the deleterious effects of heat stress on growth, livability, carcass quality, physiological, and biochemical changes in broilers (Khan et al. 2011; Safiullah et al. 2019; Ahmad et al. 2020; Hafeez et al. 2021).

For better performance, the modernistic approach focuses on the use of different dietary supplements to exploit the intrinsic potential in broiler (Khan et al. 2012a). Phytogenics are feed additives that have received huge interest in improving health, growth performance and prevention of different bacterial and parasitic diseases in broilers (Ahmad et al. 2020; Hafeez et al. 2020; Chand et al. 2021; Shuib et al. 2021). These are plant derived materials which improve the productivity of birds through improved feed utilization, antioxidant and antimicrobial activities (Khan et al. 2012b; Haq et al. 2020; Hafeez et al. 2021).

Tamarind (Tamarindus indica L.) fruit is comprised of $11 \%$ pulp, $34 \%$ seeds and $55 \%$ pulp (Biradar et al. 2017; Pal and Mukkerjee 2020). Tamarind has been known for its anti-inflammatory, cholesterol lowering 
and antioxidant functions (Chowdhury et al. 2005; Landi et al. 2007; Shridhar et al. 2014). Furthermore, it has strong carminative effect (Cabuk et al. 2003). Dried Tamarind seeds pulp (DTSP) is an excellent source of polyphenol such as oligomeric anthrocyanidins, anthrocyanidin and tannins (Pumthong 1999). Further, Gu et al. (2003) reported that DTSP contains phenolic antioxidants such as epicatechin, 3,4dihydroxyphenyl acetate, methyl 3,4- dihydroxybenzoate, 40-dihydroxyacetophenone and 2- hydroxy-30. The extract of Tamarind pulp has also exhibited antioxidant potential in vitro (Tsuda et al. 1993). The pulp of this fruit is though edible, it is still considered as an industrial waste in countries where it is grown abundantly (Galvao et al. 2019). The dry matter of pulp generated during processing of this fruit is about 50 to $65 \%$ and comprised of modest amount of crude protein $(74.8 \mathrm{~g} / \mathrm{kg})$, neutral detergent fibre $(609 \mathrm{~g} / \mathrm{kg})$, non-fiberous carbohydrate $(268 \mathrm{~g} / \mathrm{kg})$ in addition to lignin $(185 \mathrm{~g} / \mathrm{kg})$ and tannin $(75 \mathrm{~g} / \mathrm{kg})$ as reported (Santos et al. 2018; Souza et al. 2018). Despite a number of valuable phytoconstituents and properties of Tamarind pulp, there is scant scientific information on its application in broiler production and health under heat stress. Therefore, the aim of the present study was to evaluate the inclusion of different levels of DTSP on the production performance, cellular and humoral immunity, lipids profile and antioxidant status in broiler exposed to heat stress.

\section{Materials And Methods}

This experiment was carried out under the care and use of experimental animals committee, The University of Agriculture Peshawar.

\section{Preparation of DTSP powder}

Fresh fruit of Tamarind was obtained from Tamarind tree, washed with cleaned water and shade-dried for two weeks at room temperature. The pulps were ground into fine powder.

Animals and experimental designs

A total of 700 day old broiler chicks (Arbor Acres) were weighed and allocated to 28 floor pens ( 25 birds per pen) bedded with wood shavings. Each pen measured $160 \times 240 \mathrm{~cm}$, equipped with round pen feeders and drinkers. Birds had free access to feed through feeders and drinkers throughout the study. Birds were vaccinated against the infectious diseases including New Castle disease according to the standard schedule. The basal food composition is given in Table 1. Birds were kept under fluorescent lighting for $23 \mathrm{~h}$ for the first week and then a 20 light: 4 dark light cycle. Birds were exposed to a cyclic heat stress cycle as shown in Table 2. 
Table 1

Mean daily temperature and relative humidity of the experimental period

\begin{tabular}{|lll|}
\hline Hours & Temperature $\left({ }^{\circ} \mathrm{C}\right)$ & Relative humidity $(\%)$ \\
\hline $08: 00$ & 33.78 & 73.38 \\
\hline $12: 00$ & 35.36 & 96.16 \\
\hline $16: 00$ & 38.63 & 64.85 \\
\hline $20: 00$ & 35.82 & 68.85 \\
\hline $24: 00$ & 33.97 & 74.27 \\
\hline $04: 00$ & 31.56 & 76.23 \\
\hline
\end{tabular}


Table 2

Composition of basal feed and chemical composition

\begin{tabular}{|c|c|c|}
\hline Ingredients & Starter phase & Finisher phase \\
\hline Corn & 55.5 & 56.00 \\
\hline Soybean meal & 27.4 & 26.5 \\
\hline Canola meal & 6.5 & 6.00 \\
\hline Sunflower meal & 3.2 & 3.5 \\
\hline Vegetable oil & 1.8 & 1.9 \\
\hline Molasses & 1.00 & 1.00 \\
\hline Dialcium phosphate & 1.9 & 1.9 \\
\hline Limestone & 1.00 & 1.00 \\
\hline $\mathrm{NaCl}$ & 1.00 & 1.00 \\
\hline $\mathrm{NAHCO}_{3}$ & 0.2 & 0.2 \\
\hline Vitamin mineral premix & 0.3 & 0.3 \\
\hline \multicolumn{3}{|l|}{ Chemical composition } \\
\hline $\mathrm{ME}, \mathrm{kcal} / \mathrm{kg}$ & 3000 & 3150 \\
\hline Crude protein, \% & 23.5 & 21.30 \\
\hline Methionine, \% & 0.55 & 0.44 \\
\hline Lysine, \% & 1.42 & 1.23 \\
\hline Sulfur amino acids, $\%$ & 0.96 & 0.80 \\
\hline Threonine, \% & 0.95 & 0.85 \\
\hline Calcium, \% & 1.05 & 0.90 \\
\hline Phosphorus, \% & 0.50 & 0.45 \\
\hline \multicolumn{3}{|c|}{ 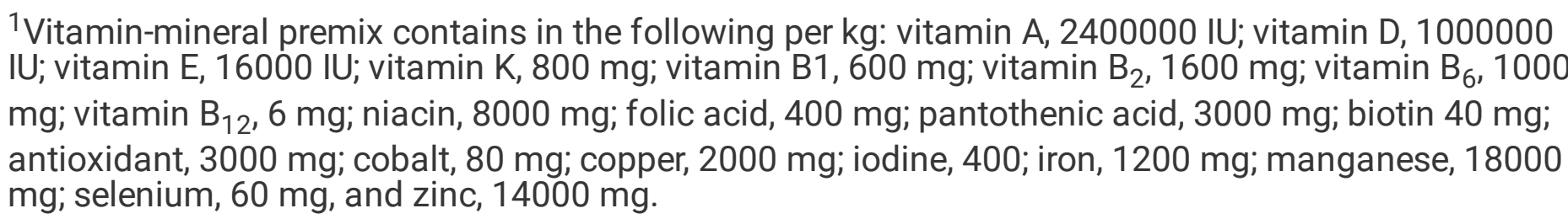 } \\
\hline
\end{tabular}

\section{Experimental protocols and samplings}

Five diets were prepared and allocated in a completely randomized design consisting of a control (basal diet) and four levels of DTSP powder at the rate of 5 (DTSP-5), 7.5 (DTSP-7.5), 10 (DTSP-10) and 12.5 (DTSP-12.5) g/kg feed for 35 days including first week as adaptation period. Feed intake, body weight 
gain and feed conversion ratio were measured per pen basis on a weekly interval and the average of each parameter for the whole period was recorded. On day 35 , three birds per pen were slaughtered and $3 \mathrm{ml}$ of blood samples were taken into two separate tubes, one with EDTA and another without EDTA. Blood without EDAT was centrifuged (3000 rpm for 10 minutes) and preserved at $-80^{\circ} \mathrm{C}$. Blood with EDTA was stored at $-4^{\circ} \mathrm{C}$ until analysis.

Serum melanodialdehyde (MDA) and paraoxonase (PON-1)

For the determination of lipid peroxidation in the serum samples, thiobarbituric acid (TBA) reaction was used as described by Ohkawa et al. (1979). The colour produced by the reaction of TBA and MDA was measured spectrophotometrically at 532nm. Blood PON-1 was determined by the method of Mackness et al. (1991) using phenol as a substrate. The working reagent was consisted of $1 \mathrm{mM}$ phenylacetate and calcium chloride and $20 \mathrm{mM}$ Tris $\mathrm{HCl}$ buffer. Change in the absorbance was recorded for five minutes at $270 \mathrm{~nm}$ after diluting the sample in 1:3 with buffer before mixing with the substrate.

\section{Cellular and humoral immunity}

Total leucocytes (TLC) and differential leucocytes were carried on blood with EDTA by the method described by Chand et al. (2016). Humoral response against the ND virus was carried out using haemagglutination inhibition test.

\section{Blood lipid profile}

Blood lipid profile of the control and treatment groups was determined with the help of commercial kits (Biocheck, UK) using chemistry analyzer.

Statistical analysis

Analysis of data was done by software (Statistix 8.1) by using Completely Randomized Design. Significant difference among the groups was computed using Tukey test at the level of $5 \%$ probability.

\section{Results}

The findings of feed intake, weight gain and FCR in broilers exposed to heat stress in response to different levels of DTSP is given in Table 2. The feed intake data did not differ between the control and the treatment groups. Body weight increased significantly $(P<0.05)$ in the DTSP fed broilers compared to the control. Similarly, FCR of the DTSP supplemented birds was significantly $(P<0.05)$ higher compared to the control broilers.

The effect of different levels of DTSP on MDA, PON1 and ND titre on broilers during heat stress is given in Table 3. The value of MDA did not change between the control and treatment groups. Blood concentration of PON1 was significantly $(P<0.05)$ higher in the DTSP-10 and DTSP-12.5 compared to the control. However, ND titre was significantly $(P<0.05)$ higher in DTSP-7, DTSP-10 and DTSP-12.5 compared to the control. 
Table 3

Mean $( \pm$ SE) feed intake, body weight and feed conversion ratio (FCR) of broilers fed with different levels of dried tamarind pulp under cyclic heat stress

\begin{tabular}{|llll|}
\hline Groups & Feed intake $(\mathbf{g})$ & Body weight $(\mathbf{g})$ & FCR $(\mathbf{g} / \mathbf{g})$ \\
\hline Control & $3260 \pm 13.42$ & $1900^{\mathrm{b}} \pm 5.43$ & $1.71^{\mathrm{a}} \pm 0.06$ \\
\hline DTSP-5 & $3170 \pm 10.32$ & $2000^{\mathrm{a}} \pm 12.40$ & $1.58^{\mathrm{b}} \pm 0.05$ \\
\hline DTSP-7.5 & $3210 \pm 8.77$ & $2007^{\mathrm{a}} \pm 11.21$ & $1.59^{\mathrm{b}} \pm 0.04$ \\
\hline DTSP-10.0 & $3230 \pm 10.09$ & $2022^{\mathrm{a}} \pm 5.90$ & $1.59^{\mathrm{b}} \pm 0.01$ \\
\hline DTSP-12.5 & $3198 \pm 12.44$ & $2011^{\mathrm{a}} \pm 9.45$ & $1.59^{\mathrm{b}} \pm 0.06$ \\
\hline P value & 0.0974 & 0.0000 & 0.0021 \\
\hline $\begin{array}{l}\text { Within the same column mean values having different superscripts are significantly different }(\mathrm{P}< \\
\text { O.05). DTSP represents Dried Tamarind seeds pulp; } 0-12.5 \text { represents Tamarind levels from } 0-\end{array}$ \\
\hline 12.5g/kg of feed
\end{tabular}

The findings of the effect of DTSP in broilers during heat stress on the blood cholesterol profile are given in Table 4. The results indicated that blood cholesterol and triglyceride were significantly $(P<0.05)$ lower in DTSP-7, DTSP-10 and DTSP-12.5 compared to the control. However, blood HDL was significantly $(\mathrm{P}<$ 005) higher in DTSP-10 and DTSP-12.5 compared to the control. Blood LDL was significantly $(P<0.05)$ lower in DTSP-7, DTSP-10 and DTSP-12.5 compared to the control.

Table 4

Mean ( \pm SE) melanodialdehyde, paraoxonase-1 and antibody titre against Newcastle disease (ND) of broilers fed with different levels of dried tamarind pulp under cyclic heat stress

\begin{tabular}{|llll|}
\hline Groups & MDA (nmole/ml) & PON1 (U/ml/min) & ND Titer \\
\hline Control & $2.54 \pm 0.15$ & $8.33^{\mathrm{b}} \pm 0.33$ & $4.00^{\mathrm{b}} \pm 0.58$ \\
\hline DTSP-5 & $2.98 \pm 0.09$ & $10.33^{\mathrm{ab}} \pm 0.88$ & $5.33^{\mathrm{ab}} \pm 0.33$ \\
\hline DTSP-7.5 & $2.59 \pm 0.09$ & $10.67^{\mathrm{ab}} \pm 0.88$ & $6.67^{\mathrm{a}} \pm 0.33$ \\
\hline DTSP-10.0 & $2.27 \pm 0.13$ & $12.00^{\mathrm{a}} \pm 0.58$ & $5.67^{\mathrm{a}} \pm 0.33$ \\
\hline DTSP-12.5 & $2.92 \pm 0.16$ & $11.67^{\mathrm{a}} \pm 0.88$ & $6.00^{\mathrm{a}} \pm 0.58$ \\
\hline P value & 0.0000 & 0.0413 & 0.0191 \\
\hline $\begin{array}{l}\text { Within the same column mean values having different superscripts are significantly different }(\mathrm{P}< \\
\text { O.05). DTSP represents Dried Tamarind seeds pulp; } 0-12.5 \text { represents Tamarind levels from } 0-\end{array}$ \\
\hline 12.5g/kg of feed
\end{tabular}

The findings of total blood leucocytes count and differential leucocytes count in broilers during heat stress is given in Table 5. Significantly $(P<0.05)$ higher TLC was found in DTSP-12.5 compared to the control and rest of the treatment groups, however, heterophil concentration was significantly $(P<0.05)$ 
lower in the same group compared to the control and the other treatment groups. However, lymphocytes increased significantly $(\mathrm{P}<0.05)$ in DTSP-7, DTSP-10 and DTSP-12.5 while monocytes significantly $(\mathrm{P}<$ $0.05)$ decreased in the same group.

Table 5

Mean $( \pm$ SE) serum lipid profile of broilers fed with different levels of dried tamarind pulp under cyclic heat stress

\begin{tabular}{|c|c|c|c|c|}
\hline Groups & $\begin{array}{l}\text { Cholesterol } \\
(\mathrm{mg} / \mathrm{dl})\end{array}$ & $\begin{array}{l}\text { Triglycerides } \\
(\mathrm{mg} / \mathrm{dl})\end{array}$ & $\begin{array}{l}\mathrm{HDL} \\
(\mathrm{mg} / \mathrm{dl})\end{array}$ & $\begin{array}{l}\text { LDL } \\
(\mathrm{mg} / \mathrm{dl})\end{array}$ \\
\hline Control & $165.67^{a} \pm 0.88$ & $148.33^{a} \pm 0.88$ & $41.00^{b} \pm 0.58$ & $93.00^{\mathrm{a}} \pm 0.58$ \\
\hline DTSP-5 & $162.67^{a} \pm 3.76$ & $137.33^{\mathrm{ab}} \pm 2.18$ & $45.00^{\mathrm{ab}} \pm 0.88$ & $91.00^{\mathrm{a}} \pm 3.47$ \\
\hline DTSP-7.5 & $145.33^{b} \pm 2.67$ & $124.67^{b} \pm 3.18$ & $45.00^{\mathrm{ab}} \pm 1.46$ & $75.00^{b} \pm 1.73$ \\
\hline DTSP-10.0 & $146.00^{\mathrm{b}} \pm 4.05$ & $122.00^{\mathrm{b}} \pm 12.01$ & $46.33^{a} \pm 2.84$ & $76.00^{b} \pm 6.36$ \\
\hline DTSP-12.5 & $141.00^{b} \pm 1.16$ & $122.00^{b} \pm 5.29$ & $48.00^{\mathrm{a}} \pm 1.73$ & $72.67^{b} \pm 0.33$ \\
\hline P-value & 0.0003 & 0.0452 & 0.0392 & 0.0031 \\
\hline \multicolumn{5}{|c|}{$\begin{array}{l}\text { Within the same column mean values having different superscripts are significantly different }(\mathrm{P}< \\
0.05) \text {. DTSP represents Dried Tamarind seeds pulp; } 0-12.5 \text { represents Tamarind levels from } 0- \\
12.5 \mathrm{~g} / \mathrm{kg} \text { of feed }\end{array}$} \\
\hline
\end{tabular}


Table 6

Mean $( \pm$ SE) total leukocyte count and differential leukocyte count of broilers fed with different levels of dried tamarind pulp under cyclic heat stress

\begin{tabular}{|c|c|c|c|c|c|c|}
\hline Groups & $\begin{array}{l}\text { TLC } \times \\
10^{3} / \mathrm{mm}^{3}\end{array}$ & $\begin{array}{l}\text { Heterophils } \\
\text { (\%) }\end{array}$ & $\begin{array}{l}\text { Lymphocytes } \\
\text { (\%) }\end{array}$ & $\begin{array}{l}\text { Monocytes } \\
\text { (\%) }\end{array}$ & $\begin{array}{l}\text { Basophils } \\
\text { (\%) }\end{array}$ & $\begin{array}{l}\text { Eosinophils } \\
\text { (\%) }\end{array}$ \\
\hline Control & $\begin{array}{l}18.33^{c} \pm \\
0.88\end{array}$ & $\begin{array}{l}29.00^{\mathrm{a}} \pm \\
0.58\end{array}$ & $59.67^{b} \pm 0.88$ & $\begin{array}{l}9.67^{\mathrm{a}} \pm \\
1.20\end{array}$ & $\begin{array}{l}1.00 \pm \\
0.58\end{array}$ & $0.67 \pm 0.88$ \\
\hline DTSP-5 & $\begin{array}{l}19.33^{C} \pm \\
0.88\end{array}$ & $\begin{array}{l}28.00^{\mathrm{a}} \pm \\
0.58\end{array}$ & $61.33^{b} \pm 1.20$ & $\begin{array}{l}8.00^{\mathrm{a}} \pm \\
0.58\end{array}$ & $\begin{array}{l}2.00 \pm \\
1.00\end{array}$ & $0.67 \pm 0.88$ \\
\hline $\begin{array}{l}\text { DTSP- } \\
7.5\end{array}$ & $\begin{array}{l}21.67^{b c} \pm \\
1.45\end{array}$ & $\begin{array}{l}26.67^{b} \pm \\
0.88^{-1}\end{array}$ & $65.67^{a} \pm 0.88$ & $\begin{array}{l}4.67^{b} \pm \\
0.88\end{array}$ & $\begin{array}{l}2.00 \pm \\
0.58\end{array}$ & $1.00 \pm 1.00$ \\
\hline $\begin{array}{l}\text { DTSP- } \\
10.0\end{array}$ & $\begin{array}{l}22.67^{\mathrm{b}} \pm \\
1.20\end{array}$ & $\begin{array}{l}24.00^{\mathrm{b}} \pm \\
0.58\end{array}$ & $68.00^{\mathrm{a}} \pm 1.16$ & $\begin{array}{l}4.00^{b} \pm \\
0.58\end{array}$ & $\begin{array}{l}2.67 \pm \\
0.88\end{array}$ & $1.33 \pm 0.34$ \\
\hline $\begin{array}{l}\text { DTSP- } \\
12.5\end{array}$ & $\begin{array}{l}24.67^{a} \pm \\
0.88\end{array}$ & $\begin{array}{l}21.33^{c} \pm \\
0.34\end{array}$ & $69.00^{a} \pm 0.58$ & $\begin{array}{l}4.67^{b} \pm \\
0.34\end{array}$ & $\begin{array}{l}3.33 \pm \\
0.66\end{array}$ & $1.67 \pm 0.34$ \\
\hline P-value & 0.0002 & 0.0000 & 0.0003 & 0.0014 & 0.3315 & 0.7723 \\
\hline
\end{tabular}

\section{Discussion}

In the present study, feed intake did not differ between the control and treatment groups of birds under heat stress conditions; however, weight gain and FCR were significantly improved in the treatment groups. Similar to our study, Aengwanich et al. (2009) reported no significant change in the feed intake and feed efficiency in broiler fed different levels of Tamarind extract during 36-42 days of age, however, weight gain was significantly higher in response to $100 \mathrm{mg} / \mathrm{kg}$ at $38^{\circ} \mathrm{C}$. In the study of Saleh et al. (2012) feed intake was decreased linearly in broiler fed with DTSP in drinking water at the increasing rate of 20,30 and $40 \mathrm{~g} / \mathrm{l}$ under thermoneutral temperature, which was attributed to the presence of anti-nutritional factors in this plant. In another study, Shinde et al. (2015) reported significant improvement in weight gain and FCR in broilers supplemented with DTSP at the rate of $250 \mathrm{~g} / 100 \mathrm{~kg}$ with depression in these traits at higher doses $(500,1000$ and $1500 \mathrm{~g} / \mathrm{kg})$ under normal temperature. It has been suggested that the pulp of Tamarind contains antioxidant (Razali et al. 2015) and antibacterial activities against the microorganisms (Daniyan and Muhammad 2008), which may result in higher growth performance in broilers. Unlike the previous studies, we did not find reduction in feed intake with the increasing level of DTSP, probably the higher doses in the current study were not enough to produce anti-nutritional factor effect. The flavonoides in Tamarind have been reported for the presence of hepatoprotective, nutrient digestibility, balancing mirobiota, antioxidative and anti-inflammatory effects (Adeniyi et al. 2021) and might have contributed to the enhanced growth in birds. 
In the current study, no significant change was observed in the serum MDA concentration in the control and treatment groups, however, PON1 concentration was increased significantly in DTSP-10 and DTSP12.5 compared to the control. In some recent studies, improved serum PON1 was observed in broilers supplemented with different natural compounds such as taurine, ginger and milkthistle under heat stress conditions (Safiullah et al. 2019; Ahmad et al. 2020; Hafeez et al. 2021). PON1 is an important HDLrelated antioxidant enzyme and its concentration has been reported to be augmented by the supplementation of antioxidants. Oxidative stress occurs due to perturbance in the balance between the oxidative stress and antioxidant capacity. Tamarind has been reported to suppress lipid peroxidaiton due to the anti-free radical activities of the phenolic compounds, two b-diketone and (-) epicatechin (Tsuda et al. 1994; Martinello et al. 2006). Limited studies have been conducted on the antioxidant activity of TDSP. In the present study, antibody titre against ND decreased in the control group and improved in DTSP-7.5, DTSP-10.0 and DTSP-12.5. The lymphocyte count is decreased during heat stress (Ahmad et al. 2020) as seen in this study and hence there is a lower antibody titre against an infection. The higher antibody titre against ND in this study seems to be due to the production of greater levels of lymphocytes in response to Tamarind supplementation.

The search for novel agents regulating blood cholesterol has gained momentum over the last few decades, resulting in a significant number of reports on natural agents with anticholesteremic activities. In view of the previous experiments, we evaluated the effect of DTSP on serum lipid profile. The seed coat of Tamarind is a low-cost source of antioxidant and exhibits antioxidant activity against thiocyanate and thiobarbituric (Pazhanivelan et al. 2008). Lipids are easily susceptible to the injury of free radicals. Compounds in Tamarid have been reported to improve the lipid profile (Martinello et al. 2006). In the current study, Tamarind pulp exhibited a significant reduction in lipid profile in serum of broilers.

Decreased serum cholesterol and triglycerides have been attributed to epicatechins contents in Tamarind (Chan et al 1999). Biradar et al. (2017) reported reduced serum cholesterol by 25 and $28 \%$ in layers fed DTSP at the level of $0.25,0.5$ and $1 \%$ at thermoneutral temperature. Similarly, Chowdhury et al. (2005) also found reduced serum cholesterol in laying hens at the level of $2 \%$ level. Shinde et al. (2015) also reported reduced serum cholesterol in broilers fed DTSP extract. Similar observations were reported by Iftekhar et al. (2006) in human and Khairunnuur et al. (2011) in rats. It is speculated that the extra cholesterol is converted into bile acid in the hepatocytes or conjugated with taurine and glycine.

Remarkably, serum HDL-cholesterol increased in the Tamarind treated birds. Biradar et al. (2017) reported increased serum HDL by $45 \%$ in Tamarind supplemented laying hens. Martinello et al. (2006) recorded increased serum HDL by $61 \%$ in hamsters in response to TDSP extract. Similar findings were also reported by Jindal et al. (2011) and Khairunnuur et al. (2011) with a significant increase in serum HDL in rats supplemented with 100 and $50 \mathrm{mg} / \mathrm{kg}$ Tamarind extract respectively. The level of serum LDL decreased significantly in DTSP-7.5, DTSP-10 and DTSP-12.5 as compared to the control during heat stress. Similar observations were also reported by Khairunnuur et al. (2011), Chor Yin lin et al. (2013) and Biradar et al. (2017) in response to Tamarind pulp in commercial layers, rats and hamsters respectively. The reduced serum LDL in Tamarind supplemented animals has been attributed to epicatechins contents 
(Luengthanaphol et al., 2004), which are known for the suppression of hypercholesterolemia by modulating lipid metabolism.

Environmental temperature is one of the most important factors affecting the immune system of broiler chickens. Exposure of the chickens to high ambient temperature causes significant physiological changes including immunosuppression and high mortality rate (Khan et al. 2012). Leucocyte count has been used as an indicator of heat stress in poultry. In the current study, TLC increased significantly in birds fed with DTSP at the rate of $12.5 \mathrm{~g} / \mathrm{kg}$. Moreover, heterophil and monocytes count increased in the control and DTSP-5 and the same were restored at the higher doses. Lymophocytes count was also lower in the control and DTSP-5, however, it was restored at higher doses. Rise in TLC is considered to enhance the immune system with increased resistance against infectious diseases and improvement in production performance. Almost similar findings were reported by Shinde et al. (2018) in broiler fed with different levels of DTSP. Aengwanich et al. (2009) reported restoration of heterophils and monocytes count in broiler under heat stress $\left(38^{\circ} \mathrm{C}\right)$ for $8 \mathrm{~h}$ at a dose rate of $400 \mathrm{mg} / \mathrm{kg}$. The resultant increase of leucocytes under heat stress has been attributed to the increased secretion of glucocorticoides. In addition, lymphocyte count was decreased in the control group and improved in broilers in Tamarind supplemented birds. Lymphopenia occurs in heat stress conditions due to increased secretion of glucocroticoides, DNA damage, lymopholysis and shift of lymphocytes from blood to the other body compartments (Compton et al. 19990; Heckert et al. 2002).

In conclusion, weight gain and FCR were improved in broilers supplemented with DTSP. PON1 was improved in DTSP-10 and DTSP-12.5 while antibody titre was greater in DTSP-7.5, DTSP-10 and DTSP12.5 in broilers during heat stress. Except DTSP-5, total cholesterol and LDL increased in the rest of the treatment groups. Furthermore, TLC increased significantly in DTSP-12.5 while lymphocytes count was greater in all the treatments except DTSP-5. Similarly, heterophils and moncytes count decreased significantly in all the treatment groups except DTSP-5.

\section{Declarations}

\section{Conflict of interest}

Authors declare no conflict of interest

\section{Ethical approval}

This study was approved by the Departmental Committee on Ethics and Animal Welfare, Faculty of Animal Husbandry \& Veterinary Sciences, The University of Agriculture, Peshawar.

\section{Competing interest}

There is no potential competing interest with this study.

\section{Consent to participate and consent to publish}


All the authors have equally participated in this study and agreed to publish this work in this journal.

\section{Authors Contribution}

MNH conducted the study and analyzed the samples. NC developed the study design. RUK edited, submitted and revised the paper.

\section{Data availability}

Data is available in the thesis.

\section{References}

1. Adeniyi, O. V., Olaifa, F. E., Emikpe, B. O., \& Ogunbanwo, S. T. (2021). Effects of dietary tamarind (Tamarindus indica L.) leaves extract on growth performance, nutrient utilization, gut physiology, and susceptibility to Aeromonas hydrophila infection in Nile tilapia (Oreochromis niloticus L.). International Aquatic Research, 13(1), 37-51.

2. Aengwanich, W., 2009. Comparative ability to tolerate heat between Thai indigenous chickens, Thai indigenous chickens crossbred and broilers by using percentage of lymphocyte. Int. J. Poult. Sci., 7:1071-1073.

3. Ahmad, M., Chand, N., R.U. Khan, Ahmad, N., Khattak, I. and Naz, S. 2020. Dietary supplementation of milk thistle (Silybum marianum): growth performance, oxidative stress and immune response in natural summer stressed broilers. Tropical Animal Health and Production 52:711-

715. doi: 10.1007/s11250-019-02060-4

4. Biradar, P.B., Kanduri, A.B., Kuldipkar, A.B., Gaikwad, N.Z. and Khan, M.A. 2017. Effect of various levels of dried tamarind pulp powder on serum and egg yolk biochemistry of layer birds. Int. J. Sci. Nat. 8 (4) 2017: 861 - 864.

5. Cabuk, M., Alcicek, A., Bozkurt, M. and Imer, N. 2003. Antimicrobial properties of the Essential oils isolated from aromatic plants and using possibility as alternative feed additives. II. National Animal Nutrition Congress 18-20 September, Antalya, Turkey, Pp: 184-187.

6. Chand, N., H. Faheem, R.U. Khan, M.S. Qureshi, I.A. Alhidary, A.M. Abudabos, 2016. Anticoccidial effect of mannanoligosacharide against experimentally induced coccidiosis in broiler. Environmental Science and Pollution Research 23:14414-14421. Impact factor 2.82.

7. Chand, N., Ali, P., Alhidary, I.A., Abelrahman, M.M., Albadani, H., Khan, M.A., Seidavi, A., Laudadio, V., Tufarelli, V. and R.U. Khan. 2021. Protective Effect of grape (Vitis vinifera) seed powder and zincglycine complex on growth traits and gut health of broilers following Eimeria tenella challenge. Antibiotics 10: 186 doi https://doi.org/10.3390/antibiotics10020186

8. Chan, P.T., Fong, W.P., Cheung, Y.L., Huang, Y., Ho, W.K.K., Chen, Z., 1999. Jasmine green tea epicatechins are hypolipidemic in hamsters (Mesocricetus auratus) fed a high fat diet. Journal of Nutrition 129, 1094-1101. 
9. Chor Yin Lim, Sarni mat junit, Mohmood Ameen Abdulla and Azlina Abdul Azziz (2013) In vivo biochemical and gene expression analyses of antioxidant activities and hypocholesterolaemic properties of Tamarindus indica fruit pulp extract; PLoS 8(7): e70058.

10. Chowdhurry, S.R., Sarker, D.K., Chowdhurry, S.D., Smith, T.K., Roy, P.K. and Wahid, M.A. 2005. Effects of dietary tamarind on cholesterol meta-bolism in laying hens. Poultry Science, 84:56-60.

11. Compton, M.M., P.S. Gibbs and L.R. Swicegood, 1990. Glucocorticoid-mediated activation of DNA degradation in avian lymphocytes. Gen. Comp. Endocrinol., 80: 68-79.

12. Daniyan, S.Y. and H.B. Muhammad, 2008. Evaluation of the antimicrobial activities and phytochemical properties of extracts of Tamaridus indica against some diseases causing bacteria. Afr. J. Biotechnol., 7: 2451-2453.

13. Galvao, J. M., Silva, T. M., Silva, W. P., Pimentel, P. R. S., Barbosa, A. M., Nascimento, T. C., ... \& Oliveira, R. L. (2020). Intake, digestibility, ingestive behavior, and nitrogen balance of goats fed with diets containing residue from tamarind fruit. Tropical animal health and production, 52(1), 257-264.

14. Gu, L., M.A. Kelm, J.F. Hammerstone, Ze. Zhang, G. Beecher, J. Holden, D. Haytowitz and R.L. Prior, 2003. Liquid chromatographic/electrospray ionization mass spectrometric studies of procyanidins in foods. J. Mass Spectro., 38: 12721280.

15. Hafeez, A., Akram, W., Sultan, A., Konca, Y., Ayasan, T., Naz, S., Shahzada, W. and R.U. Khan. 2021. Effect of dietary inclusion of taurine on performance, carcass characteristics and muscle micromeasurement in broilers under cyclic heat stress. Italian Journal of Animal Science.

16. Hafeez, A., Sohail, M., Ahmad, A., Shah, M., Din, S., Khan, I., Shuib, M., Nasrullah, Shahzada, W., Iqbal, M. and R.U. Khan. 2020. Selected herbal plants showing enhanced growth performance, ileal digestibility, bone strength and blood metabolites in broilers. Journal of Applied Animal Research 48: 448-453. doi: doi.org/10.1080/09712119.2020.1818569.

17. Haq, I., Hafeez, A. and R.U. Khan. 2020. Protective effect of Nigella sativa and Saccharomyces cerevisiae on zootechnical characteristics, fecal Escherichia coli and hematopoietic potential in broiler infected with experimental Colibacillosis. Livestock Science Volume 239, Article 104119 doi: $10.1016 /$ j.livsci.2020.104119

18. Heckert, R.A., I. Esteves, E. Russek-Cohen and R. PettitRiley, 2002. Effects of density and perch availability on the immune status of broilers. Poult. Sci., 81: 451-457.

19. Iftekhar, A.S., Rayhan, I., Quadir, M.A., Akhteruzzaman S. and Hasnat, A. (2006) Effect of Tamarindus indica fruits on blood pressure and lipid-profile in human model: an in vivo approach. Pak J Pharm Sci. 19(2):125-9.

20. Jindal V., Dhingra, D., Sharma, S., Parle, M. and Harna, R. (2011) Hypolipidemic and weight reducing activity of the ethanolic extract of Tamarindus indica fruit pulp in cafeteria diet- and sulpirideinduced obese rats. J Pharmacol Pharmacother, 2(2): 80-84.

21. Khairunnuur, FA et al. 2011. Antiobesity effect of Tamarindus indica L. pulp aqueous extract in highfat diet-induced obese rats. Journal of Natural Medicine DOI 10.1007/s11418-011-0597-8 
22. Khan, R.U., S. Naz, Z. Nikousefat, M. Selvaggi, V. Laudadio and V. Tufarelli. 2012. Effect of ascorbic acid in heat-stressed poultry. World's Poultry Science Journal, 68 (3): 477-490.

23. Khan, R.U., S. Naz, Z. Nikousefat, V. Tufarelli, M. Javadani, N. Rana and V. Laudadio. 2011. Effect of vitamin E in heat-stressed poultry. World's Poultry Science Journal, 67(3):469-478. Impact factor, 1.476.

24. Kpomasse, C.C., Oke, O.E., Houndonougbo, F.M. and Tona, K., 2021. Broiler production challenges in the tropics: A review. Veterinary Medicine and Science.

25. Landi Librandi, A.P., Chrysóstomo, T.N., Azzolini, A.E., Recchia, C.G., Uyemura, S.A., de Assis-Pandochi, A.I. (2007) Effect of the extract of Tamarind fruit of the complement system: Studies in-vitro and in hamsters submitted to a cholesterol-enriched diet. Food Chem Toxicology, 45: 1487-95.

26. Luengthanapol, S.D.. Mongkholkhajiornshilp, S. Douglas S, P. L. Douglas, L. Pengsopa and Pongamphai, S. (2004) Extraction of antioxidants from thai tamarind seed coat- preliminary experiments. J Food Eng 63:247-252.

27. Mackness, M. I., S. Arrol and P. N. Durrington. 1991. Paraoxonase prevents accumulation of lipoperoxides in low-density lipoprotein. FEBS lett. 286(1-2):152-154.

28. Martinello, F et al. 2006. Hypolipemic and antioxidant activities from Tamarindus indica L. pulp fruit extract in hypercholesterolemic hamsters. Food and Chemical Toxicology, 44 (6), 810-818.

29. Ohkawa, H., N. Ohishi and k. Yagi. 1979. Assay for lipid peroxides in animal tissues by thiobarbituric acid reaction. Anal. Biochem. 95(2): 351-358.

30. Pal, D. and Mukherjee, S., 2020. Tamarind (Tamarindus indica) Seeds in Health and Nutrition. In Nuts and Seeds in Health and Disease Prevention (pp. 171-182). Academic Press.

31. Pazhanivelan S, Amanullah MM, Vaiyapuri K, Athyamoorthi K, Radhamani S. Influence of planting techniques and amendments on the performance of tamarind (Tamarindus indicus) and changes in soil properties in rainfed alkali soil. Research Journal of Agriculture and Biological Sciences. 2008;4(4):285e288.

32. Pumthong, G., 1999. Antioxidative activity of polyphenolic compounds extracted from seed coat of Tamarindus indicus Linn. Chiangmai Mai University, Thaialnd, IV-V.

33. Razali N, Mat Junit S, Ariffin A, Ramli NS, Abdul Aziz A (2015). Polyphenols from the extract and fraction of T. Indica seeds protected HepG2 cells against oxidative stress. BMC Complementary and Alternative Medicine 15(1):438-446.

34. Safiullah, Chand, N., R.U. Khan, Naz, S., Ahmad, M. and Gul S. 2019. Effect of ginger (Zingiber officinale Roscoe) and organic selenium on growth dynamics, blood melanodialdehyde and paraoxonase in broilers exposed to heat stress. Journal of Applied Animal Research 47: 212-216.

35. Saleh, B., H. Duwa, S. S. Diarra, , T.J. Vandi, and H.A. Abdullahi. 2012. Influence of tamarind pulp on growth and carcass characteristics of broiler chickens. Res. Opin. Anim. Vet. Sci., 2(10): 511-514.

36. Santos I, Ramus R (2018) Antimicrobial resistance in aquaculture: Current knowledge and alternatives to tackle the problem. Int J Antimicr Agents 52:135-143 
37. Shinde, G.B., Kanduri, A. B., Deshmukh, G. B., Gaikwad, N.Z., Khan, M.A. and Pawar, P.H. (2015) utilization of tamarind (Tamarindus indica L.) pulp as feed supplement in broiler chicken. Unpublished M.V.Sc. thesis submitted to Maharashtra Animal and Fishery sciences university, Nagpur.

38. Shinde, G., A. Kanduri, P. Patil and M. Khan. 2018. Hematobiochemical profile of broiler chickens fed on diets supplemented with dried tamarind pulp at different intensities. Animal Science Reporter. 11(1): 10-17.

39. Shridhar, N.B. and Pradyuman Kumar (2014) Antioxidant activities of spray dried tamarind pulp powder as affected by carrier type and their addition rate. International Conference on Food, Biological and Medical Sciences (FBMS-2014) Jan. 28- 29, Bangkok (Thailand).

40. Souza, C.M., Oliveira, R.L., Voltolini, T.V., Menezes, D.R., dos Santos, N.J.A., Barbosa, A.M., Silva, T.M., Pereira, E.S., and Bezerra, L.R., 2018. Lambs fed cassava silage with added tamarind residue: Silage quality, intake, digestibility, nitrogen balance, growth performance and carcass quality, Animal Feed Science and Technology, 235, 50-59.

41. Shuaib, M., Nasrullah, Hafeez, M., Alhidary, I., Abdelrahman, M. and R.U. Khan. 2021. Effect of dietary supplementation of wildCumin (Bunium persicum) seeds on performance, nutrient digestibility and circulating metabolites in broiler chicks during the finisher phase. Animal Biotechnology (In press) doi 10.1080/10495398.2020.1844222

42. Tsuda, T., M. Watanabe, K. Ohshima, A. Yamamoto, S. Kawakishi and T. Osawa, 1994. Antioxidative components isolated from the seed of tamarind (Tamarindus indica L.). J. Agric. Food Chem., 42: 2671-2674.

43. Tsuda, T., T. Osawa, Y. Makino, H. Kato and S. Kawakishi, 1993. Screening for antioxidant activity of edible pulses. Biosci. Biotechnol. Biochem., 57: 1606-1608 